\title{
A study of masked form priming in picture and word naming
}

\author{
LUDOVIC FERRAND, JONATHAN GRAINGER, and JUAN SEGUI \\ EHESS/CNRS and René Descartes University, Paris, France
}

\begin{abstract}
We report a series of picture- and word-naming experiments in which the masked priming paradigm with prime exposures brief enough to prevent prime identification were used. Experiment 1 demonstrates that the prior presentation of the same word prime facilitates both picture and word naming independently of target frequency. In Experiments 2 and 3, primes that were pseudohomophones of picture targets produced facilitatory effects compared with orthographic controls, but these orthographically similar nonword primes did not facilitate picture naming compared with unrelated controls. On the other hand, word targets were primarily facilitated by orthographic primetarget overlap. This marked dissociation in the priming effects obtained with picture and word targets is discussed in relation to different explanations of masked form priming effects in visual word recognition and current models of picture and word naming.
\end{abstract}

Picture naming and word naming are tasks that can be accomplished quickly, efficiently, and relatively effortlessly, but this effortless performance obscures the complexity of the processes involved. This has led to the elaboration of various new techniques to study the representations and processes involved. Although relatively little is known about the nature of the representations that subtend picture and word naming, current theories all postulate that pictures require access to some form of lexical representation before they can be named, whereas printed words can be named nonlexically. In other words, picture naming is necessarily lexically mediated, whereas words can be read aloud either via a sublexical spellingto-sound conversion system or via retrieval of wholeword phonology (Coltheart, 1980, 1985; Humphreys \& Evett, 1985; Levelt et al., 1991; Morton \& Patterson, 1980; Riddoch \& Humphreys, 1987; Vitkovitch \& Humphreys, 1991). In the present article, we examine the relative contribution of lexical and nonlexical phonology in picture and word naming.

\section{Repetition Priming in Word and Object Naming}

The processing of a target word or of a target picture is facilitated if the same stimulus has been presented prior to target presentation. This effect, known as the repetition effect, is one of the most robust experimental effects reported in the field of reading. Moreover, prior experimentation has demonstrated facilitatory effects of

\footnotetext{
We thank Madeleine Leveillé for invaluable programming assistance and for editing the picture stimuli. Geoffrey Loftus, Mark Reinitz, and an anonymous reviewer provided constructive criticism of an earlier version of this article. Correspondence concerning this article should be addressed to L. Ferrand, Laboratoire de Psychologie Expérimentale, 28 rue Serpente, 75006 Paris, France.
}

repetition (or identity) priming when a prime word is masked and unavailable for conscious report in tasks such as lexical decision (Forster \& Davis, 1984; Segui \& Grainger, 1990a, 1990b; Sereno, 1991), speeded naming (Forster \& Davis, 1991; Sereno, 1991), and perceptual identification (Evett \& Humphreys, 1981; Humphreys, Besner, \& Quinlan, 1988; Humphreys, Evett, \& Taylor, 1982).

Picture-naming experiments using long stimulus onset asynchronies (SOAs), or with other words intervening between prime and target presentation (variable lag), and unmasked primes have consistently shown that the prior presentation of the same word facilitates target picture naming (e.g., Biggs \& Marmurek, 1990; Durso \& Johnson, 1979; Monsell, Matthews, \& Miller, 1992; Wheeldon \& Monsell, 1992). In particular, Durso and Johnson reported a robust repetition priming effect for picture naming, which was primed by reading the printed picture name aloud, prior to presentation (with variable lags ranging from $3 \mathrm{sec}$ to $5 \mathrm{~min}$ ). More recently, Wheeldon and Monsell have shown that picture naming is facilitated by the prior production of the name in response to a definition or in response to the visual presentation of the word, thus replicating the results of Durso and Johnson. Furthermore, Monsell et al. noted that in order to obtain the repetition priming effect, the prime and the target must share the same meaning and the same phonological form. These authors suggest that this priming effect is localized in the connection between a word's meaning and its phonological form.

One problem in interpreting the results of the research done with long SOAs is that subjects might have used predictive strategies upon noticing the relationship between certain prime-target pairs. A further problem that is specific to research in which other items intervene between prime and target presentation is the difficulty in 
separating out the episodic and lexical contributions to the observed effects. In the present study we were primarily interested in the highly automatized processes involved in normal word or picture naming, so it was essential to avoid any contamination by strategic and/or episodic factors. To this end, we used the masked priming technique (Evett \& Humphreys, 1981; Forster \& Davis, 1984).

\section{The Masked Priming Paradigm}

Previous experiments have demonstrated facilitatory effects of repetition (or identity) priming when a prime word is masked and unavailable for conscious report in word naming (Forster \& Davis, 1991; Sereno, 1991), as well as in lexical decision (Forster \& Davis, 1984; Segui \& Grainger, 1990a, 1990b; Sereno, 1991) and perceptual identification tasks (Evett \& Humphreys, 1981; Humphreys, Besner, \& Quinlan, 1988; Humphreys et al., 1982). The question to be addressed in Experiment 1 is whether these masked repetition priming effects that are observed when both primes and targets are words will also be observed when primes are words and subjects have to name picture targets. In Figure 1 we present a simple activation model of picture and word naming that will serve to clarify the predictions that can be made with respect to this first experiment. Within this theoretical framework, the masked repetition priming effect is due to the preactivation, by the prime stimulus, of some of the representations that are subsequently involved in processing the target. What is critical in this framework, with respect to whether word primes will affect picturenaming response times, is whether or not whole-word representations are partly responsible for the masked repetition priming observed with word targets. Wordnaming, lexical decision, and perceptual identification responses to word targets could all be facilitated by the preactivation of sublexical orthographic codes alone. If this were the case, then one should predict an absence of

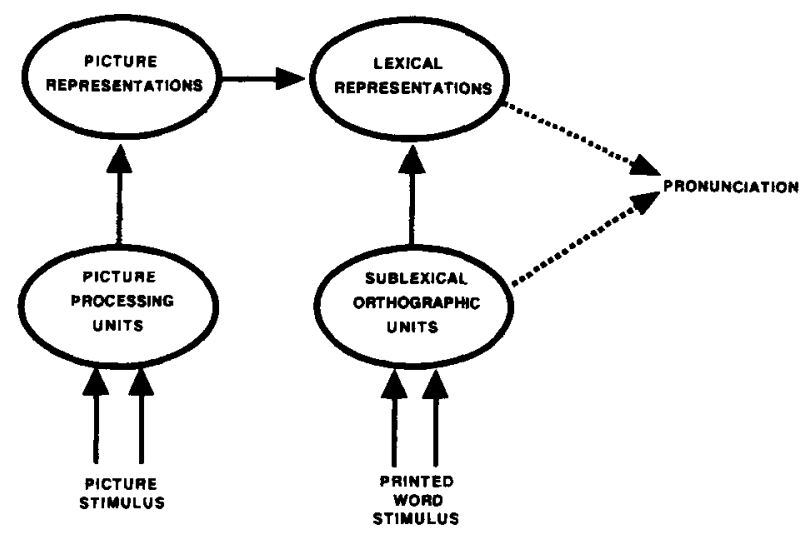

Figure 1. A simple activation model of picture and word naming. Picture targets first undergo some form of perceptual analysis (pictureprocessing units) that activates structural representations in memory, which in turn provide activation input to an articulatory code. With printed word stimuli, the articulatory code receives input from both sublexical orthographic units and lexical representations. masked repetition priming between word primes and picture targets. On the other hand, if lexical representations are involved in the masked repetition effects observed with word targets, then the model presented in Figure 1 predicts that these effects should transfer to picture naming.

In the following experiments, the targets were either line drawings of common objects or their corresponding written names. The subject's task was to name the pictures or the words as quickly as possible. Naming latencies were the main dependent variable. The experimental conditions differed with respect to the type of relationship between the prime and the target. In Experiment 1, primes and targets were either repeated or unrelated. In Experiments 2 and 3, primes and targets were phonologically related, orthographically related, or unrelated.

\section{EXPERIMENT 1A Picture Naming}

\section{Method}

Subjects. Eighteen psychology students at René Descartes University, Paris, served as subjects for course credit. All were native speakers of French, with normal or corrected-to-normal vision.

Stimuli and Design. Forty simple, black-on-white line drawings of common objects served as experimental pictures. In addition, there were 10 practice pictures. The drawings were selected from Snodgrass and Vanderwart (1980) and were digitized (Handy Scanner HS 3000) and edited with PaintBrush. Half had highfrequency names (with an average of 461 occurrences per million, ranging from a minimum of 58 to a maximum of 2,373; Trésor de la langue française, 1971), and the remaining half had low printed frequencies (with an average of 27 occurrences per million, ranging from a minimum of 2 to a maximum of 52). For each target picture, two types of word prime were selected: (1) word primes that were identical to the target picture name (e.g., TABLE-TABLE), and (2) word primes that were unrelated to the target picture name (e.g. TIRER-TABLE), but shared the same first phoneme as the target. As reported by Forster and Davis (1991), it is important to have all primes begin with the same phoneme as the target when using the naming task, otherwise different onsets may produce an interference effect in target production. Priming condition was crossed with target frequency in a $2 \times 2$ factorial design. Primetarget pairs were counterbalanced across the priming conditions across two groups of subjects so that none of the subjects saw any single prime or target picture more than once, but each subject received all four experimental conditions. Every subject saw 40 word-prime/picture-target pairs, 10 from each condition. A complete list of the stimulus words is presented in Appendix A.

Procedure. The subjects were tested individually. Before starting the experiment proper, the subjects were given a booklet including all drawings (following Schriefers, Meyer, \& Levelt, 1990). Next to each object was printed the word (translated into French) that the subjects in Snodgrass and Vanderwart (1980) had used spontaneously most frequently to name the depicted object. The subjects were asked to examine all the drawings, to study their names, and to use only those names to refer to the pictures. Word primes and target pictures were presented in the center of the screen of a personal computer with a $70-\mathrm{Hz}$ refresh rate. They appeared as black on a white background. Each trial consisted of the following sequence of four stimuli (see Figure 2). First, a forward pattern mask was presented for $500 \mathrm{msec}$. This was immediately followed by presentation of the prime word for $29 \mathrm{msec}$, which was followed immediately by a backward pattern mask for $14 \mathrm{msec}$. This was immediately followed by presentation of the target pic- 


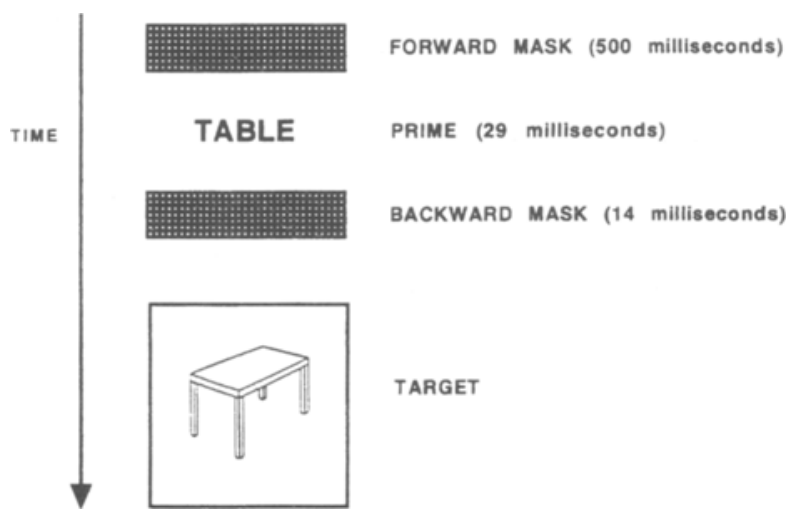

Figure 2. Sequence of events in the masked priming paradigm used in the present experiments. The subject's task was to name the target (either a picture, as in the example given, or a word) as quickly as possible.

ture presented in the same screen location as the masks. The target pictures remained on the screen until the subjects responded. Word primes were always presented in uppercase letters. The subjects were asked to fixate the middle of the forward mask. They also were instructed to name the depicted object as rapidly and as accurately as possible. The existence of a word prime was not mentioned. The computer recorded the naming times from target onset to the triggering of the voice key by the subject's response (Sennheiser MD211N microphone). The sessions were taped using an Aiwa HS-J45/J320 stereo recorder. The experimenter sat in the same room as the subject in order to check and note the responses. The next sequence followed after a 2-sec delay. Stimulus presentation was randomized, with a different order for each subject.

\section{Results}

Trials on which the subjects incorrectly named pictures, repeated their utterances, or stuttered were regarded as errors. Mean naming latencies are given in Figure 3. Latencies longer than $1,500 \mathrm{msec}$ were excluded (less than $3 \%$ of the data). Priming condition (identical prime and unrelated prime) and target frequency were entered as main factors in an analysis of variance (ANOVA) of the data for picture targets. $F$ values are reported by subject $(F 1)$ and by items $(F 2)$.

There was a significant main effect of priming condition $[F 1(1,16)=18.27, p<.001$, and $F 2(1,38)=40.27$, $p<.001]$. There was also a main effect of target frequency $[F 1(1,16)=13.59, p<.005$, and $F 2(1,38)=$ $7.62, p<.01]$. The interaction between priming condition and target frequency was not significant (all $F \mathrm{~s}<1$ ).

The error data showed the exact same pattern of effects as the RT data did, with mean values of $5.1 \%, 10.5 \%$, $1.6 \%$, and $5.5 \%$ in the low-frequency identical, lowfrequency unrelated, high-frequency identical, and highfrequency unrelated conditions, respectively. An ANOVA performed on these error data showed a significant effect of priming condition $[F 1(1,16)=11.22, p<.005$, and $F 2(1,18)=14.48, p<.005]$. The effect of target frequency was significant only by subjects $[F 1(1,16)=5.26$, $p<.05$, and $F 2(1,18)<1]$. The priming condition $\times$ target frequency interaction was not significant (both $F \mathrm{~s}<1$ ).

\section{EXPERIMENT 1B \\ Word Naming}

\section{Method}

Subjects. Eighteen psychology students at René Descartes University, Paris, served as subjects for course credit. All had normal or corrected-to-normal vision and were native speakers of French. None of the subjects had participated in Experiment 1A.

Stimuli and Design. The design was identical to that of Experiment $1 \mathrm{~A}$, except that the 40 line drawings that had served as common objects in Experiment $1 \mathrm{~A}$ were replaced by their corresponding written names. The word targets corresponding to the drawings and the word primes were all written in uppercase letters. However, for word primes, each character covered approximately $0.38^{\circ}$ of visual angle from a viewing distance of $60 \mathrm{~cm}$, whereas for word targets, each character covered approximately $0.87^{\circ}$ of visual angle. This was done in order to minimize physical overlap in the identical-prime condition.

Procedure. The procedure that was used in Experiment $1 \mathrm{~A}$ was used, except that the picture targets were replaced by their corresponding written names.

\section{Results}

Because the error rates for each condition were consistently low $(0.4 \%$ for high-frequency related words, $0.8 \%$ for unrelated; $0.7 \%$ for low-frequency related words, $1.2 \%$ for unrelated), an ANOVA was not conducted. Mean naming latencies are given in Figure 4. The latencies were trimmed by applying a 1,000-msec cutoff (less than $1 \%$ of the data rejected). Priming condition (identical prime and unrelated prime) and target frequency were entered as main factors in an ANOVA of the word data. There was a significant main effect of priming condition $[F 1(1,16)=103.21, p<.001$, and $F 2(1,38)=102.97, p<.001]$, which showed that iden-

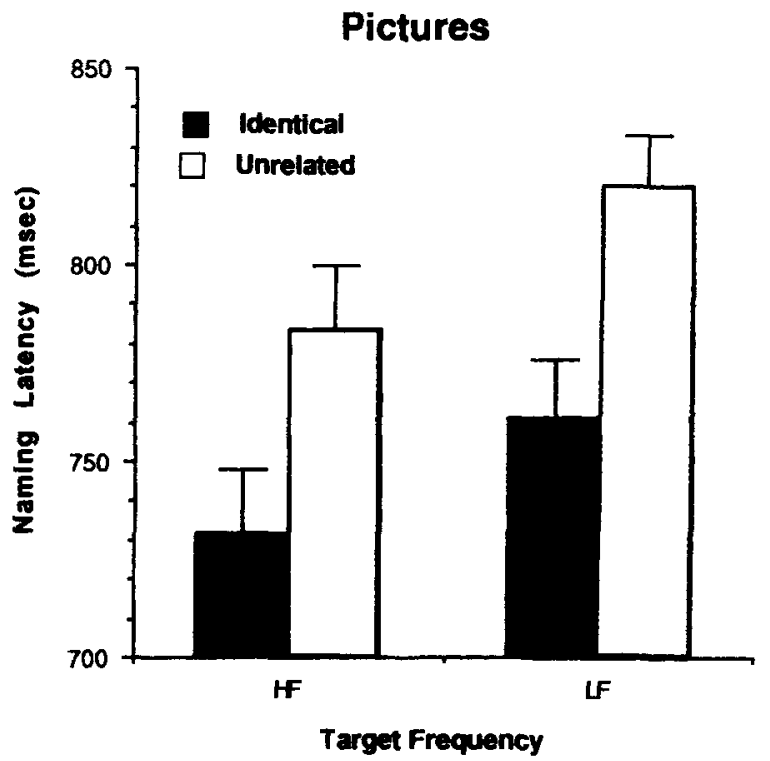

Figure 3. Mean naming latencies (in milliseconds) in Experiment $1 \mathrm{~A}$ (picture naming), as a function of type of prime-target relation and target frequency (HF, high frequency; LF, low frequency). Vertical bars represent standard errors. 


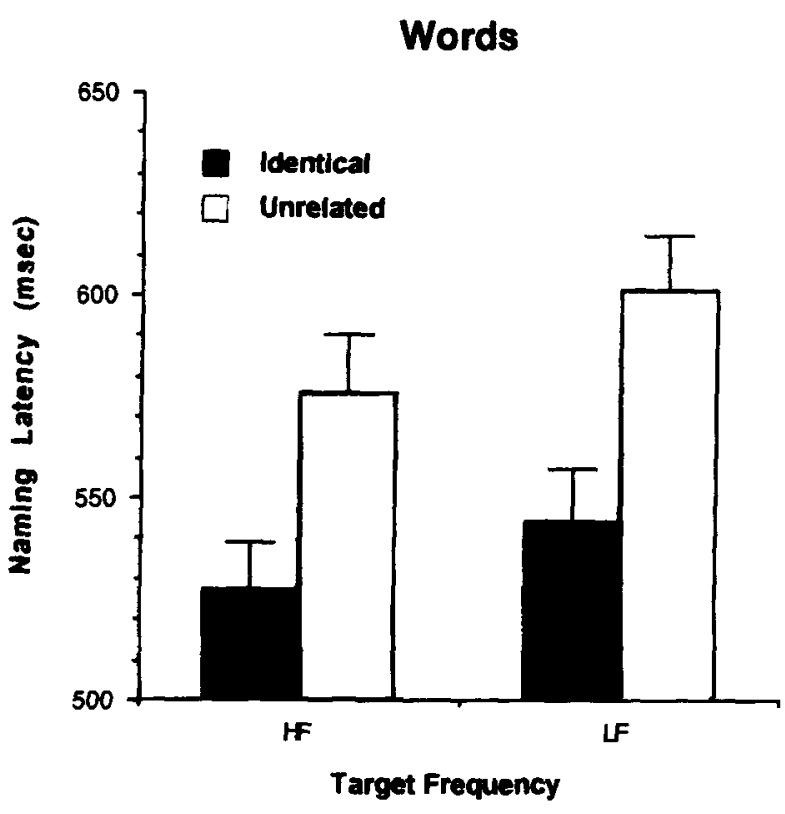

Figure 4. Mean naming latencies (in milliseconds) in Experiment $2 B$ (word naming) as a function of type of prime-target relation and target frequency (HF, high frequency; LF, low frequency). Vertical bars represent standard errors.

tical pairs were responded to more rapidly than unrelated pairs. There was also a main effect of target frequency $[F 1(1,16)=6.72, p<.05$, and $F 2(1,38)=8.89, p<$ $.005]$. There was no interaction between priming condition and target frequency (both $F \mathrm{~s}<1$ ).

Estimated visibility of the primes. Following Forster and Davis (1984), a post hoc measure of prime visibility was performed by using the stimuli of Experiments $1 \mathrm{~A}$ and $1 \mathrm{~B}$. In order to assess the amount of information available to awareness, the subjects were informed of the existence of a prime word. Their task was to decide whether the prime word was nominally the same as the picture or word target; in other words, they performed a forced-choice same-different judgment. Of course, the subjects were informed that half the trials would contain prime words that were the same as the target and the remaining half would contain prime words that differed from the target. The subjects were encouraged to take this into account when making their decision. Twenty new subjects were tested-10 in the picture target conditions and the other 10 in the word target conditions. The results are presented in Table 1 . The overall percentcorrect rate was $49 \%$ for picture naming and $48 \%$ for word naming. None of the subjects got more than $55 \%$ correct. Moreover, as shown in Table 1, the overall percentcorrect value was almost identical for high-frequency and low-frequency targets (independently of whether the targets were pictures or words). This absence of a frequency effect provides further evidence that the subjects had very little information available from the prime stimuli.
This estimate is better than that reported by Forster and Davis (1984). Their overall percent-correct value was $59 \%$ (slighty better than chance performance). This is probably due to the fact that the primes in the present experiments were presented for $29 \mathrm{msec}$ (vs. $60 \mathrm{msec}$ in Forster and Davis's experiment) and were masked by a backward pattern mask. Therefore, it seems safe to conclude that very little precise information about the prime as a whole was available for conscious identification.

\section{Discussion}

The results of Experiment 1 clearly show that the naming of both pictures and words is facilitated when preceded by masked identical word primes (relative to unrelated controls), and that the magnitude of this repetition effect is very similar for both types of target. The fact that picture target naming was facilitated by the prior masked presentation of the corresponding name as a prime suggests that the brief presentation $(29 \mathrm{msec})$ of a written word is sufficient to activate lexical representations that are involved in naming picture targets.

According to activation-based models of visual word recognition (McClelland \& Rumelhart, 1981; Morton, 1979), masked repetition priming can be explained by the preactivation of the target's lexical representation by the prime stimulus. This can also be applied to activationbased models of speech production (Dell, 1988; Stemberger, 1985) in order to explain the effects on picture naming. Here, one has to make the additional assumption that the lexical representations activated by printed word primes are used not only to recognize and name printed words, but also to name pictures. The fact that the effect sizes were comparable in word and picture naming in Experiments $1 \mathrm{~A}$ and $1 \mathrm{~B}$ and that they corresponded to the effect sizes typically observed in lexical decision (Forster \& Davis, 1984; Segui \& Grainger, 1990a, 1990b) and naming (Forster \& Davis, 1991; Sereno, 1991) adds further support to this analysis. Furthermore, low- and high-frequency picture and word targets produced comparable effects in Experiment 1, thus replicating prior observations of an absence of interactivity of masked repetition priming effects with target frequency in tasks such as lexical decision (Forster \& Davis, 1984; Segui \& Grainger, 1990a, 1990b; Sereno, 1991), perceptual identification (Humphreys, Besner, \& Quinlan, 1988), and naming (Forster \& Davis, 1991; Sereno, 1991).

Table 1

Percentage of Correct Responses (PC) with Standard Errors

(SE) in a Forced-Choice Same-Different Judgment Task

(Is the Prime Nominally the Same as the Target?) for Picture and Word Targets Used in Experiments $1 \mathrm{~A}$ and 1B, as a Function of High or Low Target Frequency

\begin{tabular}{|c|c|c|c|c|c|}
\hline \multirow[b]{3}{*}{ Experiment } & \multirow[b]{3}{*}{ Target } & \multicolumn{4}{|c|}{ Target Frequency } \\
\hline & & \multicolumn{2}{|c|}{ High } & \multicolumn{2}{|c|}{ Low } \\
\hline & & $\mathrm{PC}$ & $S E$ & $\mathrm{PC}$ & $S E$ \\
\hline $1 \mathrm{~A}$ & pictures & 50 & 4.47 & 48 & 5.01 \\
\hline $1 \mathrm{~B}$ & words & 49 & 5.18 & 47 & 4.68 \\
\hline
\end{tabular}


An additional point that should be noted here is the replication of the frequency effect for picture naming observed by Oldfield and Wingfield (1965) and Huttenlocher and Kubicek (1983); pictures with frequently used names were named more rapidly and more accurately than pictures with infrequently used names. Moreover, Wingfield (1968) showed that the frequency effect was not due to the time needed to recognize the object, suggesting that this effect would appear to be located in the phase of lexical access. Within the framework of the interactive activation model of speech production developed by Stemberger (1985), entries in the lexicon that are frequently activated develop higher resting levels of activation than entries that are less frequently activated (see McClelland \& Rumelhart, 1981). They therefore attain critical levels of activation necessary for generating an articulatory response more rapidly than nodes that are less frequently activated (see also Dell, 1986, 1988). Within the framework of the cascade model of picture naming developed by Humphreys, Riddoch, and Quinlan (1988), name frequency is also assumed to affect access to phonological representations.

\section{EXPERIMENT 2}

In the previous discussion it was argued, on the basis of the results of Experiment 1, that briefly presented word primes activate lexical representations in memory that underlie the process of picture naming. In the simple model presented in Figure 1, these lexical representations are amodal. According to this model, primes that are orthographically similar to targets should also facilitate performance in both word and picture naming, since any orthographic overlap between prime and target will allow the prime stimulus to preactivate the target's lexical representation. Phonological overlap between prime and target should not, on the other hand, affect picture and word naming relative to orthographic controls in this simple model. Experiment 2 was designed to test these predictions.

A number of recent studies (Bajo \& Canas, 1989; Collins \& Ellis, 1992; Lupker \& Williams, 1989; McEvoy, 1988 ) have reported that phonologically similar word or nonword primes do facilitate picture naming in conditions in which primes are clearly visible or audible. Other studies, using an interference paradigm, suggest that phonologically similar word (or nonword) primes facilitate picture naming relative to unrelated controls (Lupker, 1982; Meyer \& Schriefers, 1991; Rayner \& Posnansky, 1978; Schriefers, Meyer, \& Levelt, 1990). In particular, Rayner and Posnansky presented pictures with a nonword superimposed in the middle; the visual and phonological similarity of the nonword to the actual picture name was varied. Nonwords that preserved phonological features of the name of the pictured item produced faster naming latencies than nonwords that preserved few phonological features. In a more recent study, Schriefers et al., using a paradigm in which the distractor words were presented auditorily, found that phonologically interfering words (e.g., sHEET when the target was SHEEP) facilitated picture-naming latencies. However, our previous criticisms of repetition priming studies using long prime exposures and/or long lags between prime and target also apply here.

Turning to word recognition, a large body of evidence has recently been collected, which shows that phonologically and/or orthographically related masked primes influence performance in visual word recognition tasks such as perceptual identification (Grainger \& Ferrand, 1994b; Lukatela \& Turvey, 1990; Perfetti \& Bell, 1991; Perfetti, Bell, \& Delaney, 1988) and lexical decision (Ferrand \& Grainger, 1992, 1993). In all of the abovecited experiments, performance to word targets was superior when they were preceded by phonologically related (pseudohomophone) primes (e.g., mayd-MAID) than when they were preceded by orthographic controls (e.g., mard-MAID). The above experiments all converge to suggest that these facilitatory effects are due to the automatic, prelexical activation of phonological information in visual word recognition.

However, this growing body of evidence that shows early phonological involvement in tasks such as lexical decision and perceptual identification contrasts sharply with the lack of evidence in the naming task (see, e.g., Peter, Lukatela, \& Turvey, 1990). Thus, in Experiments $2 \mathrm{~A}$ and $2 \mathrm{~B}$, we examined whether phonologically and/or orthographically similar masked nonword primes affect word- and picture-naming performance. To do this, we used pairs of stimuli that allowed us to separate phonological priming from orthographic priming. This was done in order to specify the type of representation (phonological, orthographic, or both) involved in picture and word naming.

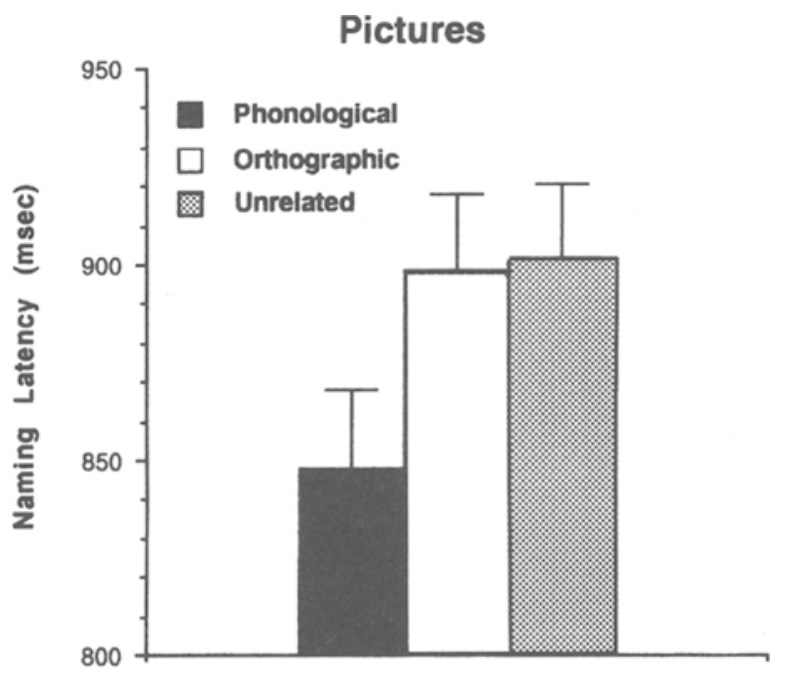

Priming Condition

Figure 5. Mean naming latencies (in milliseconds) in Experiment $2 A$ (picture naming) as a function of type of prime-target relation. Vertical bars represent standard errors. 


\section{EXPERIMENT 2A Picture Naming}

\section{Method}

Subjects. Thirty psychology students at René Descartes University, Paris, served as subjects for course credit. None of the subjects had participated in the previous experiments. All were native speakers of French, with normal or corrected-to-normal vision.

Stimuli and Design. Thirty simple, black-on-white drawings of common objects, taken from Snodgrass and Vanderwart (1980), served as picture targets. The average frequency of the names of the pictures was 234 occurrences per million, ranging from a minimum of 34 to a maximum of 89,209 (Trésor de la langue française, 1971). For each target picture, three types of nonword prime were selected: (1) nonword primes that were both homophonic and orthographically similar (differing by only one letter) to the written name of the picture target (e.g., piez-PIED), (2) nonword primes that were orthographically related but not homophonic with the written name of the picture target (e.g., pien-PIED), and (3) nonword primes that were unrelated to the target picture name but that shared the same first phoneme as the target (e.g., peul-PIED). Primetarget pairs were rotated across the priming conditions across three groups of subjects so that none of the subjects saw any single nonword prime or target picture more than once, but each subject received all three experimental conditions. Every subject saw 30 nonword-prime/picture-target pairs-10 from each condition. The subjects were presented with 10 practice pictures before beginning the experiment proper. A complete list of the verbal stimuli is presented in Appendix B.

Procedure. This was the same as that in Experiment 1A.

\section{Results}

Mean naming latencies are given in Figure 5. The latencies were trimmed by applying a 1,500-msec cutoff (less than $5 \%$ of the data rejected). An ANOVA of the naming latencies for picture targets was performed with priming condition (homophonic and orthographically similar prime, orthographically similar but nonhomophonic prime, unrelated prime) entered as the main factor.

There was a significant main effect of priming condition $[F 1(2,54)=4.77, p<.05$, and $F 2(2,58)=14.86, p<$ $.001]$. Planned comparisons between orthographically similar pseudohomophone primes and orthographically similar but nonhomophone primes (i.e., effects of phonological facilitation) show a $51-\mathrm{msec}$ facilitation effect $[F 1(1,27)=8.55, p<.01$, and $F 2(1,29)=29.18, p<$ $.001]$. On the other hand, planned comparisons between orthographically similar but nonhomophonic primes and unrelated primes (i.e., effects of orthographic facilitation) failed to reach significance $[F 1(1,27)<1$, and $F 2(1,29)<1]$.

The error data showed the same pattern of effects as the RT data, with mean values of $2 \%, 5.3 \%$, and $7 \%$ for the pseudohomophone, orthographic, and unrelated conditions, respectively. An ANOVA performed on the error data showed a significant effect of priming condition $[F 1(2,54)=3.42, p<.05$, and $F 2(2,58)=3.84, p<$ $.05]$. Planned comparisons showed a phonological priming effect $[F 1(1,27)=4.94, p<.05$, and $F 2(1,29)=$ $3.22, .05<p<.10$ ], but no orthographic priming effect (both $F \mathrm{~s}<1$ ).

\section{EXPERIMENT 2B Word Naming}

\section{Method}

Subjects. Thirty psychology students at René Descartes University, Paris, served as subjects for course credit. All had normal or corrected-to-normal vision and were native speakers of French. None of the subjects had participated in the previous experiments.

Stimuli and Design. The design was the same as that in Experiment $2 \mathrm{~A}$, except that the 30 target pictures used in Experiment $2 \mathrm{~A}$ were replaced by their corresponding written names.

Procedure. The procedure was the same as that in Experiment 2B.

\section{Results}

Mean naming latencies are given in Figure 6. The latencies were trimmed by applying a 1,000-msec cutoff (less than $1 \%$ of the data rejected). Once again, the mean error rates were too low to conduct an ANOVA $(0.5 \%$, $0.8 \%$, and $1 \%$ for the pseudohomophone, orthographic, and unrelated conditions, respectively). An ANOVA of the naming latencies for word targets was performed with priming condition as the main factor. There was a significant main effect of priming condition $[F 1(2,54)=$ $24.97, p<.001$, and $F 2(2,58)=23.04, p<.001]$. Planned comparisons between orthographically similar pseudohomophone primes and orthographically similar but nonhomophonic primes (i.e., effects of phonological facilitation) failed to reach significance $[F 1(1,27)<1$, and $F 2(1,29)=1.28]$. On the other hand, planned comparisons between orthographically similar but nonhomophonic primes and unrelated primes (i.e., effects of orthographic facilitation) showed a 32-msec facilitation effect $[F 1(1,27)=25.26, p<.001$, and $F 2(1,29)=$ $41.18, p<.001]$.

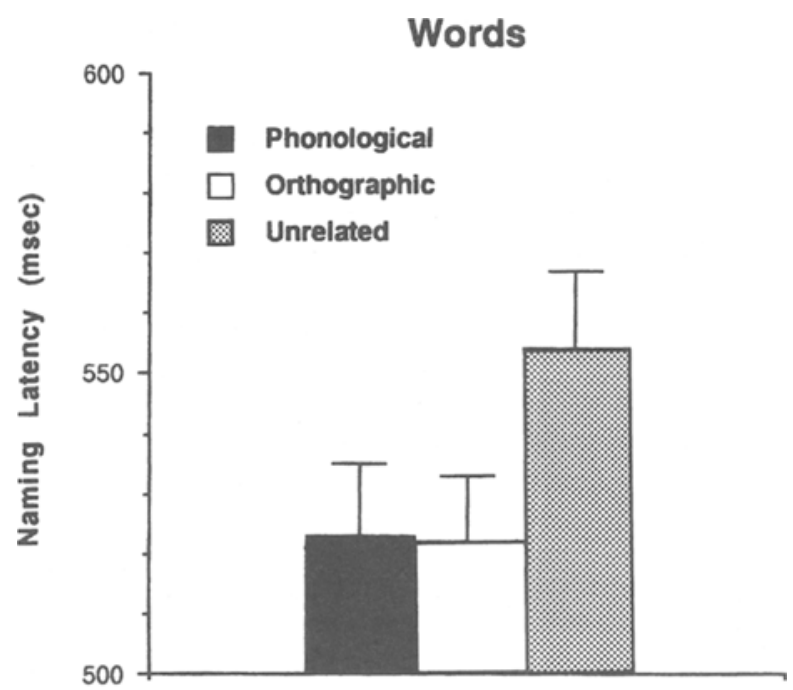

Priming Condition

Figure 6. Mean naming latencies (in milliseconds) in Experiment $2 B$ (word naming) as a function of type of prime-target relation. Vertical bars represent standard errors. 


\section{Discussion}

The results show that picture naming was strongly and reliably facilitated by the prior presentation of a masked pseudohomophone prime, contrary to the predictions of the simple model of picture and word naming presented in Figure 1. Moreover, in terms of percentage of naming latencies, the magnitude of this facilitation effect $(+6 \%)$ was similar to the identity priming effect observed in Experiment 1A $(+6.8 \%)$. On the other hand, a masked orthographic prime failed to facilitate picture naming, once more contradicting the predictions of the simple model. These results suggest that the representation underlying the masked repetition priming effect in picture naming is phonological. Such a representation would be equally strongly activated by a word and its corresponding pseudohomophone. Furthermore, the fact that phonological overlap was greater between the orthographically similar prime and the picture name than between the unrelated prime and the picture name, and that picturenaming latencies did not differ with these two types of primes, suggest that the phonological representation subserving the pseudohomophone priming effect corresponds to the whole-word phonological representation.

Word naming was, on the other hand, facilitated by the prior presentation of both a pseudohomophone prime and an orthographically related prime. Since reaction times in these two priming conditions did not differ, although degree of phonological overlap with the target was $100 \%$ in the pseudohomophone condition and $50 \%$ on average in the orthographic condition, this implies that the facilitation observed relative to the unrelated condition can be essentially attributed to orthographic prime-target overlap. The fact that the magnitude of this facilitation effect $(+6 \%$ facilitation) was considerably smaller than the repetition priming effect observed in Experiment 1B ( $+8.9 \%$ facilitation) adds support to this argument. This suggests that the masked priming of word naming is primarily sensitive to orthographic primetarget overlap, whereas primed picture naming is primarily sensitive to phonological overlap. We return to this point in the General Discussion.

\section{EXPERIMENT 3}

Experiment 3 was conducted as a direct replication of Experiment $2 \mathrm{~A}$, in order to firmly establish the finding that picture naming is facilitated by the prior presentation of a masked pseudohomophone prime relative to both orthographic and unrelated controls. In order to reduce the naming latencies and variability observed in Experiment $2 \mathrm{~A}$, we used a small number of highly trained subjects. This enabled a more direct comparison of the picture-naming and word-naming latencies observed in Experiment 2B.

\section{Method}

Subjects. Nine well-trained subjects, all psychology students at René Descartes University, Paris, participated in Experiment 3. All were native speakers of French, with normal or corrected-to-

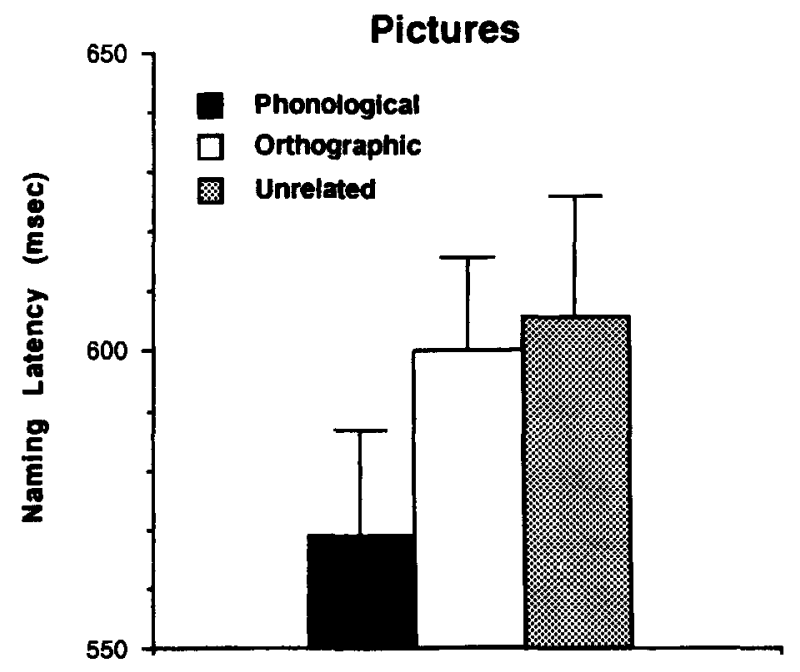

\section{Priming Condition}

Figure 7. Mean naming latencies (in milliseconds) in Experiment 3 (picture naming) as a function of type of prime-target relation. Vertical bars represent standard errors.

normal vision. None of them had participated in the previous experiments.

Stimuli and Design. They were the same as in Experiment 2A.

Procedure. This was the same as in Experiment 2A, except that before the experiment proper, the subjects were given extensive practice naming the picture targets without the corresponding primes. This was done in order to decrease picture-naming latencies. Thus, each subject ran 10 practice sessions with all the experimental picture targets. After this extensive training, the experiment was run in the same way as Experiment $2 \mathrm{~A}$.

\section{Results}

Mean picture-naming latencies for each priming condition are given in Figure 7. The latencies were trimmed by applying a 1,000 -msec cutoff (less than $1 \%$ of the data rejected). Because the mean error rates for each priming condition were consistently too low $(0.7 \%, 1 \%$, and $1.2 \%$ for the pseudohomophone, orthographic, and

Table 2

Mean Naming Latencies (RT, in Milliseconds) With

Standard Errors (SE) for Each of the 9 Subjects

in Experiment 3 (Picture Naming) as a Function of Type of Prime-Target Relation

\begin{tabular}{|c|c|c|c|c|c|c|}
\hline \multirow[b]{2}{*}{ Subjects } & \multicolumn{2}{|c|}{$\begin{array}{c}\text { Orthographically } \\
\text { Similar } \\
\text { Pseudohomophone } \\
\text { Prime }\end{array}$} & \multicolumn{2}{|c|}{$\begin{array}{c}\text { Orthographically } \\
\text { Similar } \\
\text { Prime } \\
\end{array}$} & \multicolumn{2}{|c|}{$\begin{array}{c}\text { Unrelated } \\
\text { Prime }\end{array}$} \\
\hline & RT & $S E$ & RT & $S E$ & RT & $S E$ \\
\hline 1 & 567 & 16 & 613 & 14 & 657 & 22 \\
\hline 2 & 523 & 11 & 584 & 12 & 538 & 11 \\
\hline 3 & 561 & 11 & 616 & 13 & 608 & 14 \\
\hline 4 & 597 & 12 & 627 & 12 & 618 & 21 \\
\hline 5 & 472 & 13 & 505 & 17 & 517 & 14 \\
\hline 6 & 569 & 24 & 592 & 14 & 643 & 21 \\
\hline 7 & 578 & 17 & 600 & 14 & 615 & 21 \\
\hline 8 & 700 & 37 & 683 & 33 & 684 & 37 \\
\hline 9 & 551 & 12 & 582 & 14 & 575 & 12 \\
\hline
\end{tabular}




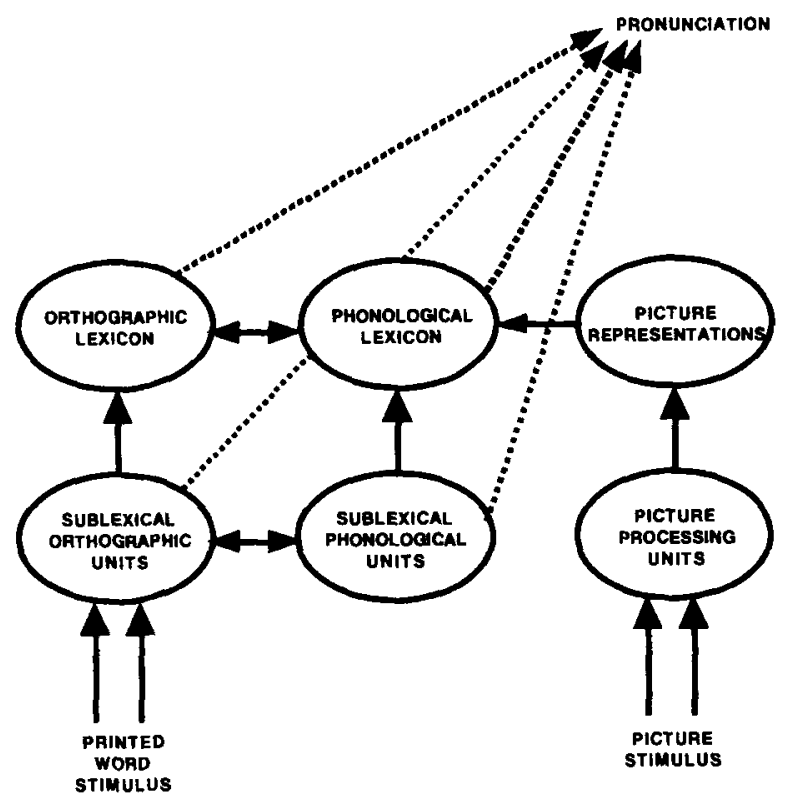

Figure 8. An extended activation model of picture and word naming implementing the distinction between an orthographic and a phonological lexicon. Picture representations activate whole-word phonological representations in memory that then send activation on to the articulatory output. In the case of printed words, the articulatory output recelves activation from both sublexical and lexical orthographic and phonological codes.

unrelated conditions, respectively), an ANOVA was not conducted. An ANOVA of the naming latencies for picture targets was performed with priming condition as the main factor.

There was a significant main effect of priming condition $[F 1(2,16)=9.16, p<.005$, and $F 2(2,58)=13.09$, $p<.001]$. Planned comparisons between orthographically similar pseudohomophone primes and orthographically similar but nonhomophonic primes (i.e., the effects of phonology) showed a 31-msec facilitation effect $[F 1(1,8)=17.26, p<.005$, and $F 2(1,29)=9.94, p<$ $.005]$. On the other hand, planned comparisons between orthographically similar but nonhomophonic primes and unrelated primes (i.e., the effects of orthography) failed to reach significance $[F 1<1$, and $F 2(1,29)=2.46]$. Table 2 shows the individual reaction time data for all 9 subjects, with the corresponding standard errors for the three priming conditions. As can be seen from this table, the effects of phonological priming are very stable across subjects.

Using a small number of highly trained subjects, Experiment 3 provides a direct replication of Experiment $2 \mathrm{~A}$. When picture targets were preceded by the written presentation of the same phonological form (i.e., a pseudohomophone), a large and robust facilitation effect was observed in the masked priming paradigm. Moreover, this facilitation effect was very similar in size to that observed in Experiment 2A (6.1\% facilitation in
Experiment 3 compared with $6.0 \%$ facilitation in Experiment 2A).

\section{GENERAL DISCUSSION}

The present experiments show that picture naming is facilitated by the prior masked visual presentation of the same phonological word form. This robust and large facilitation effect was obtained independently of whether the prime was the same word or a pseudohomophone. Since this effect was obtained in conditions in which primes were not identifiable by subjects, these results suggest that it is subtended by automatic, fast-developing processes common to picture naming and word recognition. Moreover, the fact that strong effects of pseudohomophone primes were observed with picture targets implies that phonological representations have been activated from orthographic information even in the extremely limiting prime-presentation conditions used in the present experiments.

The simple model of picture and word naming presented in the introduction (Figure 1) predicted that pseudohomophone primes should not affect picture or word naming when these priming effects are measured against appropriate orthographic controls. In Figure 8, we present an extension of the simple model of Figure 1 that allows it to capture the results of the present experiments. This extension involves adding sublexical phonology and introducing a distinction between wholeword orthographic and phonological representations (see Grainger \& Ferrand, 1994a, 1994b). On presentation of a word stimulus, activation will spread from sublexical orthographic units onto sublexical phonological

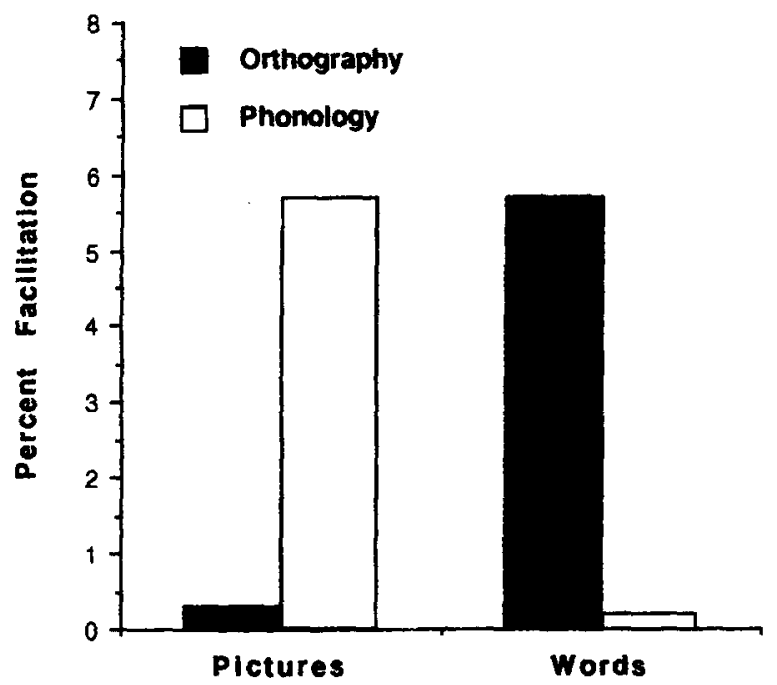

Figure 9. Net percent facilitation effects observed in Experiment 2A (picture naming) and Experiment 2B (word naming) to targets preceded by phonologically related primes (compared with orthographic controls) and orthographically related primes (compared with unrelated controls). 
units and whole-word representations in the orthographic and phonological lexica. The final articulatory output is assumed to depend on both the activity of whole-word units and sublexical units. Due to the time course of information flow in this model, when reading printed words aloud, the articulatory output will receive activation first from sublexical orthographic units. With picture targets, on the other hand, the articulatory output will receive activation first from whole-word phonological representations. Thus, speeded word naming will be dominated by sublexical orthography, whereas picture naming will be mainly influenced by activity in the phonological lexicon.

According to this model, the pseudohomophone priming effect in picture naming results from the preactivation in memory of the phonological representation corresponding to the picture name. This interpretation is strengthened by the fact that the priming effect for picture naming is similar in size when the prime is either the same word or when it is a pseudohomophone $(+6.8 \%$ facilitation in Experiment $1 \mathrm{~A}$ and $+6 \%$ facilitation in Experiment 2A). A printed prime word or its pseudohomophone equivalent (e.g., TREE-TREA) will both activate the corresponding whole-word phonological representation in memory and therefore facilitate subsequent picture naming much to the same extent. Sublexical orthographic units that are shared by a word prime and a picture target name will not facilitate picture naming over and above unrelated controls, since these sublexical orthographic units that are activated by the prime stimulus will not receive further support upon presentation of a picture target.

The second important result of the present experiments is the fact that naming latencies to word targets remained unaffected by pseudohomophone primes compared with the orthographic condition. This result suggests that phonological information extracted from the prime stimulus has little influence on the word-naming process. On the other hand, the word-naming process proved to be sensitive to prime-target orthographic overlap-a result that has been recently replicated in a related series of experiments (Grainger \& Ferrand, 1994a; see also Manso de Zuniga, Quinlan, \& Humphreys, 1988). Figure 9 presents this marked dissociation in the priming effects observed in the present experiments in terms of percent facilitation. In the masked priming paradigm, picture naming is principally influenced by the preactivation of phonological representations, whereas word naming seems to be primarily influenced by primetarget orthographic overlap.

The dissociation in priming effects obtained with picture and word targets presented in Figure 9 can be given the following interpretation within the framework sketched in Figure 8 . A briefly presented pseudohomophone prime can activate the corresponding phonological word unit in memory, thus giving rise to facilitation in picture naming, but will result in an even stronger activation of the corresponding sublexical orthographic codes since these are closer to the input. Since, in word naming, the articulatory output receives information from these sublexical orthographic codes before it receives information from lexical codes, it is the orthographic overlap between prime and target that will mainly influence the time it takes subjects to name word targets.

From a methodological point of view, the masked priming technique has once again proven its utility in the study of basic cognitive processes. Already well tested in the field of visual word recognition, the present experiments have demonstrated its successful application to word and picture naming. Further research with this technique should help to elucidate the complex process of transforming a visual image into a set of articulatory commands.

\section{REFERENCES}

Bajo, M. T., \& Canas, J. J. (1989). Phonetic and semantic activation during picture and word naming. Acta Psychologica, 72, 105-115.

Biggs, T. C., \& Marmurek, H. H. C. (1990). Picture and word naming: Is facilitation due to processing overlap? American Journal of Psychology, 103, 81-110.

Collins, A. F., \& Ellis, A. W. (1992). Phonological priming of lexical retrieval in speech production. British Journal of Psychology, 83, 375-388.

Coltheart, M. (1980). Reading, phonological recoding and deep dyslexia. In M. Coltheart, K. E. Patterson, \& J. Marshall (Eds.), Deep dyslexia (pp. 197-226). London: Routledge \& Kegan Paul.

Coltheart, M. (1985). Cognitive neuropsychology and the study of reading. In M. I. Posner \& O. S. M. Marin (Eds.), Attention and performance $X I$ (pp. 3-37). Hillsdale, $\mathrm{NJ}$ : Erlbaum.

DELL, G. S. (1986). A spreading activation theory of retrieval in language production. Psychological Review, 93, 283-321.

DELL, G.S. (1988). The retrieval of phonological forms in production: Tests of predictions from a connectionist model. Journal of $\mathrm{Mem}$ ory \& Language, 27, 124-142.

Durso, F. T., \& Johnson, M. K. (1979). Facilitation in naming and categorizing repeated pictures and words. Journal of Experimental Psychology: Human Learning \& Memory, 5, 449-459.

EvetT, L. J., \& Humphreys, G. W. (1981). The use of abstract graphemic information in lexical access. Quarterly Journal of Experimental Psychology, 33A, 283-321.

Ferrand, L., \& Grainger, J. (1992). Phonology and orthography in visual word recognition: Evidence from masked nonword priming. Quarterly Journal of Experimental Psychology, 45A, 353-372.

FerRand, L., \& Grainger, J. (1993). The time course of orthographic and phonological code activation in the early phases of visual word recognition. Bulletin of the Psychonomic Society, 31, 119-122.

ForsteR, K. I., \& DAvis, C. (1984). Repetition priming and frequency attenuation in lexical access. Journal of Experimental Psychology: Learning, Memory, \& Cognition, 10, 680-698.

ForSTER, K. I., \& Davis, C. (1991). The density constraint on formpriming in the naming task: Interference effects from a masked prime. Journal of Memory \& Language, 30, 1-25.

Grainger, J., \& FERRAND, L. (1994a). Masked orthographic and phonological priming in visual word recognition and naming: Cross-task comparisons. Manuscript submitted for publication.

Grainger, J., \& Ferrand, L. (1994b). Phonology and orthography in visual word recognition: Effects of masked homophone primes. Journal of Memory \& Language, 33, 218-233.

Humphreys, G. W., Besner, D., \& Quinlan, P. T. (1988). Event perception and the word repetition effect. Journal of Experimental Psychology: General, 117, 51-67.

Humphreys, G. W., \& EvetT, L. J. (1985). Are there independent lexical and non-lexical routes in word processing? An evaluation of the dual route theory of reading. Behavioral \& Brain Sciences, 8, 689-740. 
Humphreys, G. W., EvetT, L. J., \& TAYLOR, D. E. (1982). Automatic phonological priming in visual word recognition. Memory \& Cog nition, 10, 576-590.

Humphreys, G. W., Riddoch, M. J., \& Quinlan, P. T. (1988). Cascade processes in picture identification. Cognitive Neuropsychology, $\mathbf{5}$, 67-103.

HutTenlocher, J., \& KUBiceK, L. F. (1983). The source of relatedness effects on naming latency. Journal of Experimental Psychology: Learning, Memory, \& Cognition, 9, 486-496.

Levelt, W. J. M., Schriefers, H., Vorberg, D., Meyer, A. S., PechManN, T., \& Havinga, J. (1991). The time course of lexical access in speech production: A study of picture naming. Psychological Review, 98, 122-142.

Lukatela, G., \& Turvey, M. T. (1990). Phonemic similarity effects and prelexical phonology. Memory \& Cognition, 18, 128-152.

LUPKER, S. J. (1982). The role of phonetic and orthographic similarity in picture-word interference. Canadian Journal of Psychology, 36, 349-367.

LUPKER, S. J., \& WiLliams, B. A. (1989). Rhyme priming of pictures and words: A lexical activation account. Journal of Experimental Psychology: Learning, Memory, \& Cognition, 15, 1033-1046.

Manso de Zuniga, C. M., Quinlan, P. T., \& Humphreys, G. W. (1988, March). Task constraints on priming with masked primes. Paper presented at the meeting of the Experimental Psychology Society, Reading, England.

McClelland, J. L., \& Rumelhart, D. E. (1981). An interactive activation model of context effects in letter perception: Part 1. An account of basic findings. Psychological Review, 88, 375-405.

McEvor, C. L. (1988). Automatic and strategic processes in picture naming. Journal of Experimental Psychology: Learning, Memory, \& Cognition, 14, 618-626.

Meyer, A. S., \& Schriefers, H. (1991). Phonological facilitation in picture-word interference experiments: Effects of stimulus onset asynchrony and types of interfering stimuli. Journal of Experimental Psychology: Learning, Memory, \& Cognition, 17, 1146-1160.

Monsell, S., MatThews, G. H., \& Miller, D. C. (1992). Repetition of lexicalization across languages: A further test of locus of priming. Quarterly Journal of Experimental Psychology, 44A, 763-783.

MORTON, J. (1979). Facilitation in word recognition: Experiments causing change in the logogen model. In P. A. Kolers, W. E. Wrolstad, \& M. Bouma (Eds.), Processing visible language (Vol. 1, pp. 259-268). New York: Plenum.

Morton, J., \& Patterson, K. E. (1980). A new attempt at an interpretation, or an attempt at a new interpretation. In M. Coltheart, K. E. Patterson, \& J. C. Marshall (Eds.), Deep dyslexia (pp. 91-118). London: Routledge \& Kegan Paul.

OLDFIELD, R. C., \& WINGFIELD, A. (1965). Response latencies in nam- ing objects. Quarterly Journal of Experimental Psychology, 17, 273-281.

Perfetti, C. A., \& Bell, L. C. (1991). Phonemic activation during the first $40 \mathrm{~ms}$ of word identification: Evidence from backward masking and priming. Journal of Memory \& Language, 30, 473-485.

Perfetti, C. A., Bell, L. C., \& Delaney, S. M. (1988). Automatic (prelexical) phonetic activation in silent reading: Evidence from backward masking. Journal of Memory \& Language, 27, 59-70.

Peter, M., Lukatela, G., \& Turvey, M. T. (1990). Phonological priming: Failure to replicate in the rapid naming task. Bulletin of the Psychonomic Society, 28, 389-392.

RAYNER, K., \& PosNANSKY, C. (1978). Stages of processing in word identification. Journal of Experimental Psychology: General, 107, 64-80.

Riddoch, M. J., \& HumphreYs, G. W. (1987). Picture naming. In G. W. Humphreys \& M. J. Riddoch (Eds.), Visual object processing: $A$ cognitive neuropsychological approach (pp. 107-144). London: Erlbaum.

Schriefers, H., Meyer, A. S., \& Levelt, W. J. M. (1990). Exploring the time course of lexical access in production: Picture-word interference studies. Journal of Memory \& Language, 29, 86-102.

SEGUI, J., \& GRAINGER, J. (1990a). Masquage et effet de répétition du mot: Sa nature et sa localisation fonctionnelle [Masked priming and the word repetition effect]. L'Année Psychologique, 90, 345-357.

SegUi, J., \& GRAINGER, J. (1990b). Priming word recognition with orthographic neighbors: Effects of relative prime-target frequency, Journal of Experimental Psychology: Human Perception \& Performance, 16, 65-76.

SERENo, J. A. (1991). Graphemic, associative, and syntactic priming effects at a brief stimulus onset asynchrony in lexical decision and naming. Journal of Experimental Psychology: Learning, Memory, \& Cognition, 17, 459-477.

Snodgrass, J. G., \& VANDERWART, M. (1980). A standardised set of 260 pictures: Norms for name agreement, familiarity, and visual complexity. Journal of Experimental Psychology: Human Learning \& Memory, 6, 174-215.

Stemberger, J. P. (1985). An interactive activation model of language production. In A. W. Ellis (Ed.), Progress in the psychology of language (Vol. 1, pp. 143-186). Hillsdale, NJ: Erlbaum.

Trésor de la langue française (1971). Nancy: CNRS.

VITKOVITCH, M., \& HumphrEys, G. W. (1991). Perseverant responding in speeded naming to pictures: It's in the links. Journal of Experimental Psychology: Learning, Memory, \& Cognition, 17, 664-680.

WHEELdon, L. R., \& MONSELL, S. (1992). The locus of repetition priming of spoken word production. Quarterly Journal of Experimental Psychology, 44A, 723-761.

WINGFIELD, A. (1968). Effects of frequency on identification and naming of objects. American Journal of Psychology, 81, 226-234.

\begin{tabular}{lll} 
& \multicolumn{3}{c}{ APPENDIX A } \\
& Stimuli Used in Experiment I & \\
\hline Word Target & Identical Prime & Unrelated Prime \\
\hline PAIN & High Frequency & \\
PIED & PAIN & PEAU \\
TABLE & PIED & PART \\
LIVRE & TABLE & TRAIN \\
VERRE & LIVRE & LARME \\
BOUTON & VERRE & VENIR \\
ETOILE & BOUTON & BARQUE \\
DRAPEAU & ETOILE & EFFORT \\
OREILLE & DRAPEAU & DIAMANT \\
MONTAGNE & OREILLE & OBTENIR \\
CLEF & MONTAGNE & MINISTRE \\
MAIN & CLEF & CAMP \\
PIPE & MAIN & MERE \\
JAMBE & PIPE & PARC \\
LAMPE & JAMBE & JUGER \\
SOLEIL & LAMPE & LECON \\
& SOLEIL & SENTIR
\end{tabular}


APPENDIX A (Continued)

\begin{tabular}{|c|c|c|}
\hline COUTEAU & Couteau & CLIENTE \\
\hline ECHELLE & ECHELLE & ESTIMER \\
\hline CHAPEAU & CHAPEAU & CHOISIR \\
\hline \multirow[t]{2}{*}{ CEINTURE } & CEINTURE & COURRIER \\
\hline & Low Frequ & \\
\hline SCIE & SCIE & SNOB \\
\hline CLOU & CLOU & CAGE \\
\hline POIRE & POIRE & PLANT \\
\hline BAGUE & BAGUE & BOURG \\
\hline PEIGNE & PEIGNE & PANTIN \\
\hline BANANE & BANANE & BELIER \\
\hline PICHET & PICHET & PAGODE \\
\hline AMPOULE & AMPOULE & ANCHOIS \\
\hline TAMBOUR & TAMBOUR & TORTURE \\
\hline POUBELLE & POUBELLE & PERCHOIR \\
\hline JUPE & JUPE & JOUE \\
\hline TASSE & TASSE & TRONC \\
\hline PINCE & PINCE & PROUE \\
\hline POUCE & POUCE & PLOMB \\
\hline BROSSE & BROSSE & BUFFET \\
\hline CERISE & CERISE & CIMENT \\
\hline BOUGIE & BOUGIE & BALCON \\
\hline CITRON & CITRON & CERNER \\
\hline MARTEAU & MARTEAU & MESSAGE \\
\hline FAUTEUIL & FAUTEUIL & FOUGERE \\
\hline
\end{tabular}

APPENDIX B

Stimuli Used in Experiment 2

\begin{tabular}{|c|c|c|c|}
\hline Word Target & $\begin{array}{l}\text { Orthographically } \\
\text { Similar } \\
\text { Pseudohomophone } \\
\text { Prime } \\
\end{array}$ & $\begin{array}{c}\text { Orthographically } \\
\text { Similar } \\
\text { Prime }\end{array}$ & $\begin{array}{c}\text { Unrelated } \\
\text { Prime }\end{array}$ \\
\hline BRAS & BRAT & BRAI & BORL \\
\hline CERF & CERS & CERL & CAUN \\
\hline CHAT & CHAX & CHAP & CHUL \\
\hline CLEF & CLEE & CLEU & CLON \\
\hline GANT & GANS & GANE & GEUF \\
\hline LOUP & LOUS & LOUN & LIDE \\
\hline LUGE & LUJE & LUBE & LAIN \\
\hline LAMPE & LANPE & LARPE & LOURM \\
\hline PIED & PIEZ & PIEN & PEUL \\
\hline PIPE & PYPE & POPE & PLIR \\
\hline ROUE & ROUS & ROUN & REIL \\
\hline TOIT & TOIS & TOIN & TABE \\
\hline SCIE & SCIS & SCIC & SEUN \\
\hline CROIX & CROIE & CROIN & CLEUN \\
\hline MAIN & MAIM & MAIL & MOUR \\
\hline NOEUD & NOEUX & NOEUR & NISE \\
\hline PINCE & PIMCE & PIRCE & PLOUR \\
\hline POIRE & POIRT & POIRI & PANIR \\
\hline SINGE & SINJE & SINLE & SORLT \\
\hline TIGRE & TYGRE & TOGRE & TOULS \\
\hline VERRE & VEIRE & VENRE & VILER \\
\hline GRUE & GRUS & GRAL & GLEU \\
\hline NOIX & NOIS & NOIL & NEUL \\
\hline PAIN & PAIM & PAIL & PLOR \\
\hline PORC & PORE & PORL & PAME \\
\hline POIDS & POIDT & POIDE & PLUR \\
\hline PRISE & PRIZE & PRINE & PUIR \\
\hline DENT & DANT & DUNT & DISE \\
\hline PEIGNE & PEYGNE & PELGNE & PRAMER \\
\hline LIVRE & LYVRE & LOVRE & LORME \\
\hline
\end{tabular}

(Manuscript received June 28, 1993;

revision accepted for publication October 6,1993 .) 